\title{
THE IRONIC EXPLORATION FROM ABSTRACT EXPRESSIONISM TO
} MINIMALISM

Tina Porwal* ${ }^{1}$

${ }^{*}$ Research Scholar, DAVV, Indore, INDIA

*Correspondence Author: sethiya.tina@gmail.com

\begin{abstract}
:
An art movement in sculpture and painting that began in the 1950s and emphasized extremesi mplification of form and colour. A school of abstract painting and sculpture that emphasizes extreme simplification of form, as by the use of basic shapes and monochromatic palettes of primary colors, objectivity, and anonymity of style. Also called ABC art, minimal art, reductivism, rejective art. The early 1960s brought about a significant shift in American art, largely in reaction to the critical and popular success of the highly personal and expressive painterlygestures of Abstract Expressionism. Minimalist artists produced pared-down threedimensional objects that have no resemblance to any real objects. Their new vocabulary of simplified, geometric forms made from humble industrial materialschallenged traditional notions of craftsmanship, the illusion of three dimensions, or spatial depth, and the idea that a work of art must be one of a kind.
\end{abstract}

Keywords:

Abstract, Minimalism, Sculpture, Painting, ART, Expressionism.

\section{INTRODUCTION}

This article attempts to introduce a significant purpose to explore the gap between - and improbable proximity of - abstract expressionism and minimalism.

Minimal Art is a school of abstract painting and sculpture where any kind of personal expression is kept to a minimum extinct, in order to give the work a completely literal presence. The resulting work is characterized by extreme simplicity of form and a deliberate lack of expressive content.

Minimal Art emerged as a trend in the late 1950s and flourished particularly in the 1960s and 1970s. It is also referred to as $\mathrm{ABC}$ art, literal art, literalism, reductivism, and rejective art.

The main principle is that not the artist's expression, but the reality of work is its medium and materials. Or we can say: a work of art should not refer to anything other than itself. As minimalist painter Frank Stella once said: "What you see is what you see".

In 1929, the Ukrainian author David Burlyuk wrote:

"Minimalism derives its name from the minimum of operating means. Minimalist painting is purely realistic - the subject being the painting itself."

Abstract Art can be a painting or sculpture that does not portray a person, place or thing in the natural world -- even in an extremely misrepresented or overemphasize way. Therefore, the subject of the work is based on what you see: colour, shapes, brushstrokes, size, and scale and in some cases, the process. 


\section{INTERNATIONAL JOURNAL Of RESEARCH - GRANTHAALAYAH \\ A knowledge Repository}

Art

Abstract art began in 1911 with such works as Picture with a Circle (1911) by the Russian artist Wassily Kandinsky (1866-1944).

The experience of the abstract requires in the artist a particular mental or spiritual attitude which is fundamentally same for all branches of the visual arts. Only the means of expression differ, and the nature of the experience is of a particular kind, often expressible equally well in drawing, painting or sculpture though in some cases limited to one of the three modes of expression. In this respect abstract art has not altered the traditional situation.

This "seeing" is no more a deliberate thought process than the painter's poetic creative vision of impressions of real things. Part abstractions have always been associated with artistic vision. Medieval chimaeras and fabulous beasts which were never seen in reality in form or colour express imaginary concepts, however naturalistically they are represented. They were the result of a desire to express some intangible, spiritual content of an imagined, or even of the visible world.

\section{HISTORY}

Through much of the 1950s, the dominant art movement in the United States was Abstract Expressionism. The expressionist artists seeked to express their personal emotions through their art.

A highly popular branch of Abstract Expressionism was called Action Painting. This was a style of painting in which paint is spontaneously dribbled, splashed or smeared onto the canvas.

In the early 1960's, a new movement emerged; Minimal Art. The Minimalists felt that Action Painting (and as such, Abstract Expressionism) was too pretentious, insubstantial and personal. They rejected the idea that art should reflect the personal expression of its creator. Instead, they adopted the point of view that a work of art should not refer to anything other than itself. Their goal was to make their works totally objective, inexpressive, and non-referential.

One of the first painters to be specifically linked with Minimalism was (the former Abstract Expressionist) Frank Stella. Stella's instantly acclaimed minimalist Black Paintings (19581960), in which regular bands of black paint were separated by very thin pinstripes of unpainted canvas, contrasted the emotional canvases of Abstract Expressionism.

A historic moment for the art movement was the group exhibit "Primary Structures", held in 1966 at the Jewish Museum in New York. Amongst others, it featured work of Donald Judd, Carl Andre, Dan Flavin, Sol LeWitt, Robert Morris, and Tony Smith and really put Minimal Art as a name on the map.

\section{OBJECTIVES}




\section{INTERNATIONAL JOURNAL Of RESEARCH - GRANTHAALAYAH \\ A knowledge Repository} Art

The Minimalists' emphasis on eliminating signs of authorship from the artwork (by using simple, geometric forms, and courting the appearance of industrial objects).

In order to achieve this, they attempted to remove all suggestions of self-expressionism from the art work, such as:

- Complexity of form

- Themes

- Composition

- Representation, reference or association

- Social comment

- Elements of traditional work

- Meaning, sentiment, emotion

- Any other signs of personal expression of the artist, his guiding hand or thought processes

\section{PAINTING}

Minimalist painters make a great effort to create objects with presence, which can be seen at their basic physical appearance.

Minimalist paintings are usually precise and 'hard-edged', referring to the abrupt transitions between colour areas. They incorporate geometric forms, often in repetitive patterns, resulting in flat, two-dimensional space. Colour areas are generally of one solid, unvarying colour. Colours were normally unmixed, coming straight from the tube. The colour palette is often limited. Through this use of only line, solid colour, geometric forms and shaped canvas, the minimalist artists combined paint and canvas in such a way that the two became inseparable.

Well-known minimalist painters from the 1960's and 1970's:
- Ellsworth Kelly
- Kenneth Noland
- Robert Ryman
- Frank Stella
- Barnett Newman

For a comprehensive overview of all minimalist artists: 


\section{INTERNATIONAL JOURNAL Of RESEARCH - GRANTHAALAYAH \\ A knowledge Repository}

Art

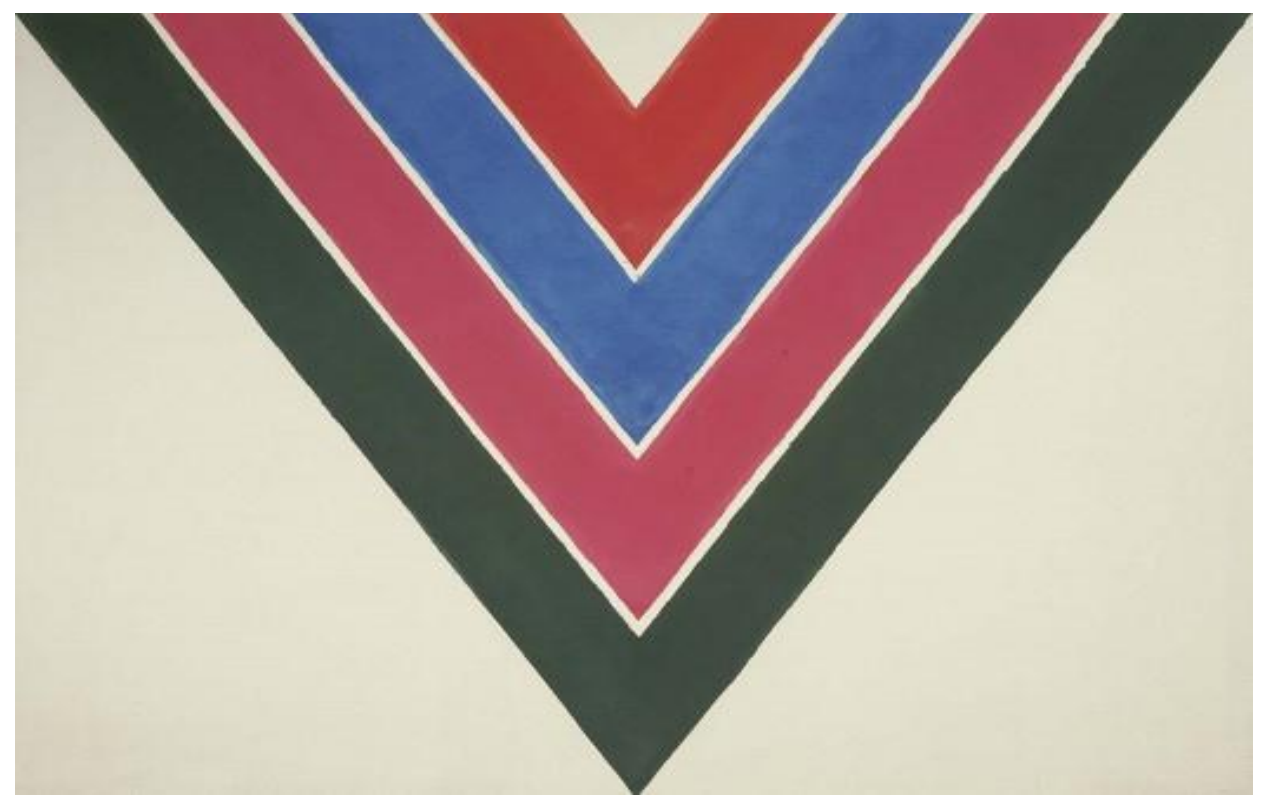

Figure 1: "Shoot", by Kenneth Noland (1964). Material: Acrylic on canvas. Size: 103' 3/4" x 126' 3/4" (263.5 x 321.9 cm). Collection: Smithsonian American Art Museum Museum

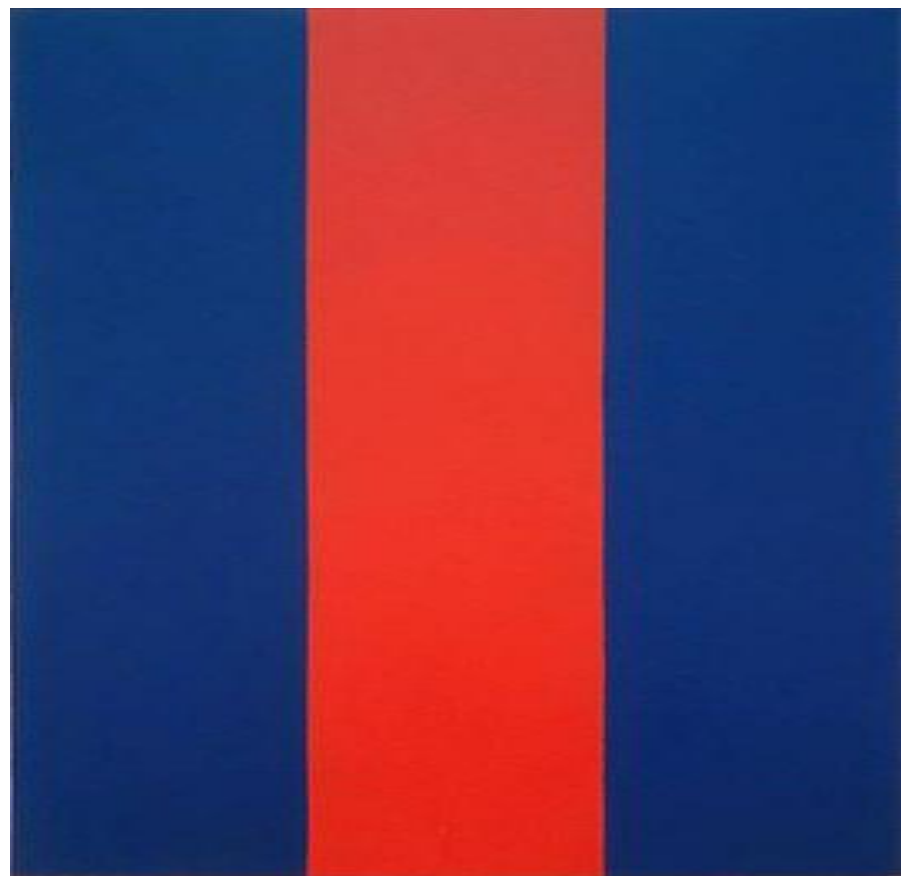

Figure 2: "Voice of Fire", by Barnett Newman(1967). Material: Acrylic on canvas. Collection: Smithsonian American Art Museum Museum 


\section{INTERNATIONAL JOURNAL Of RESEARCH - GRANTHAALAYAH \\ A knowledge Repository} Art

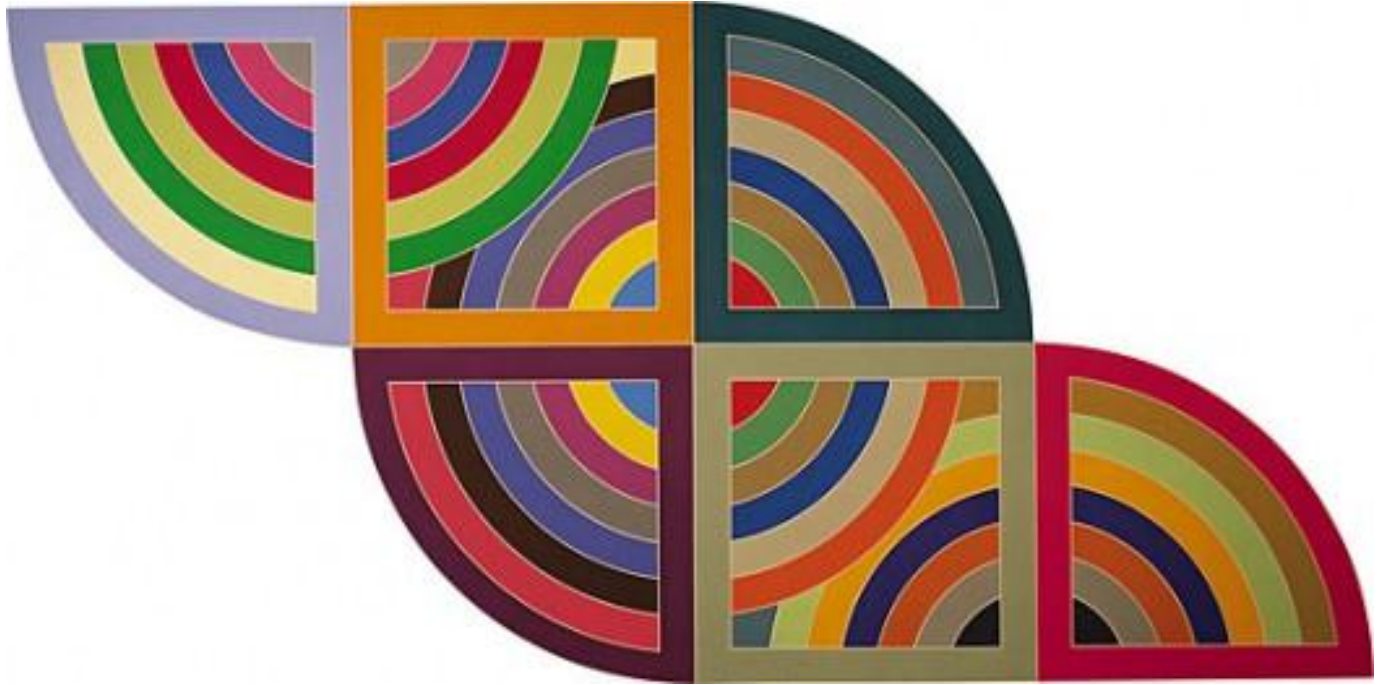

Figure 3: "Harran II", by Frank Stella (1967). Material: Polymer and fluorescent polymer paint on canvas. Size: 10 x 20 feet $(304.8$ x $609.6 \mathrm{~cm})$. Collection: Guggenheim Museum, New York.

Figure 4: "Twin", by Robert Ryman (1966). Material: Oil on cotton. Size: 6' 3 3/4" x 6' 3 7/8" (192.4 x $192.6 \mathrm{~cm})$. Collection: MoMA. 


\section{INTERNATIONAL JOURNAL Of RESEARCH - GRANTHAALAYAH \\ A knowledge Repository} Art

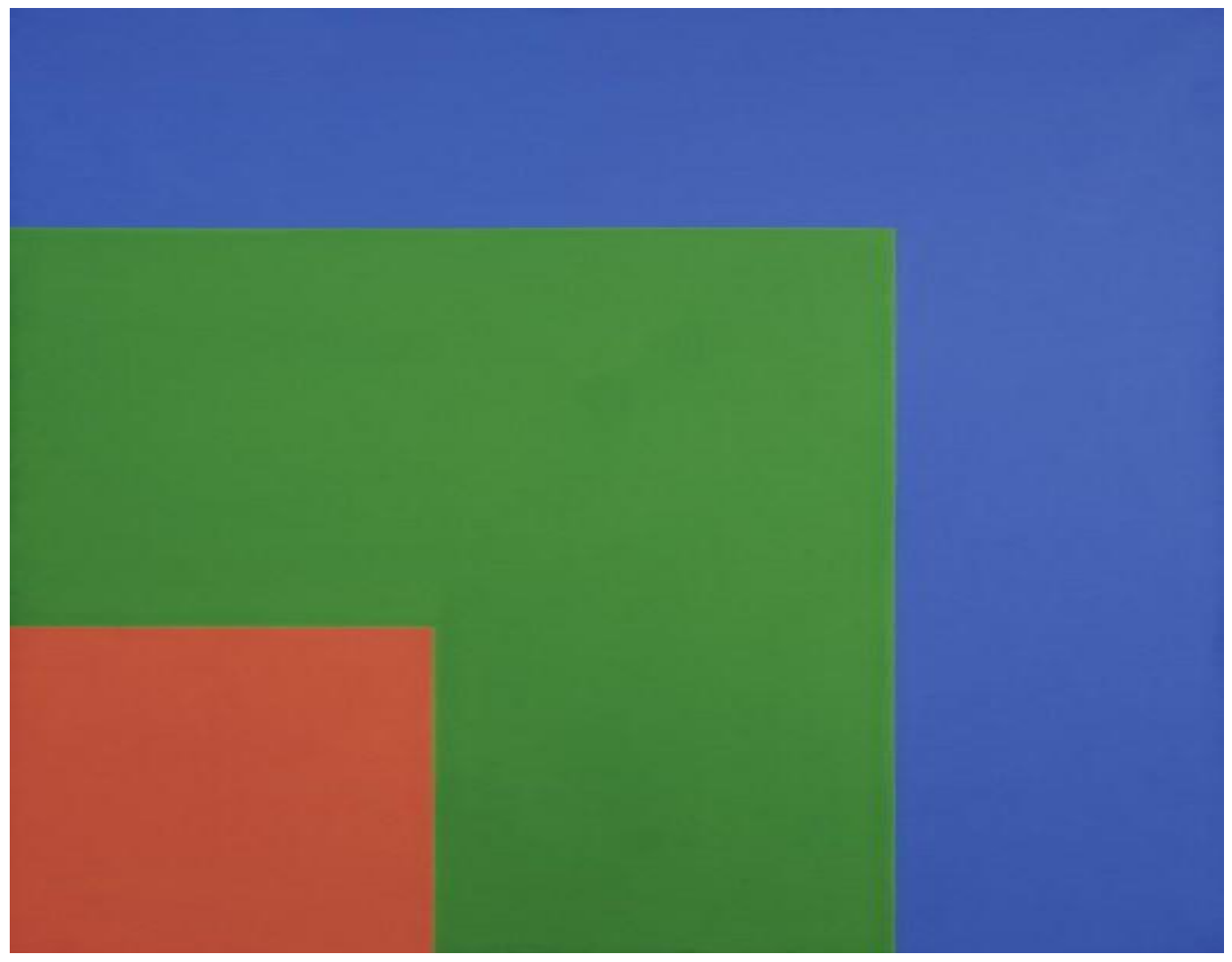

Figure 5: "Red Green Blue", by Ellsworth Kelly (1964). Material: Oil on canvas. Size: unframed 90 x 66 inches. Collection: Walker Art Center.

\section{SCULPTURE}

Sculptor Sol LeWitt once wrote that "the most interesting characteristic of the cube is that it is relatively uninteresting." This comment speaks to what Minimalism aims to achieve, which is to use objects in and for themselves, and not as symbols or as representations.

The non-hierarchical character of the grid-based compositions challenged the notion of artistic originality, while the visual rhythms were strongly reminiscent of a production line.

Minimalist artist preferred industrial materials, prefabricated and/or mass-produced: fibreglass, Plexiglass, plastic, sheet metal, plywood, and aluminium. Steel, glass, concrete, wood and stone are also returning materials. The materials were either left raw (or hardly processed by the artist), or were solidly painted with bright industrial colours. 


\section{INTERNATIONAL JOURNAL Of RESEARCH - GRANTHAALAYAH \\ A knowledge Repository}

Art

Well-known minimalist sculptors from the 1960's and 1970's:

- Carl Andre

- Dan Flavin

- Donald Judd

- Sol LeWitt

- Robert Morris

- Tony Smith

For a comprehensive overview of all minimalist artists:

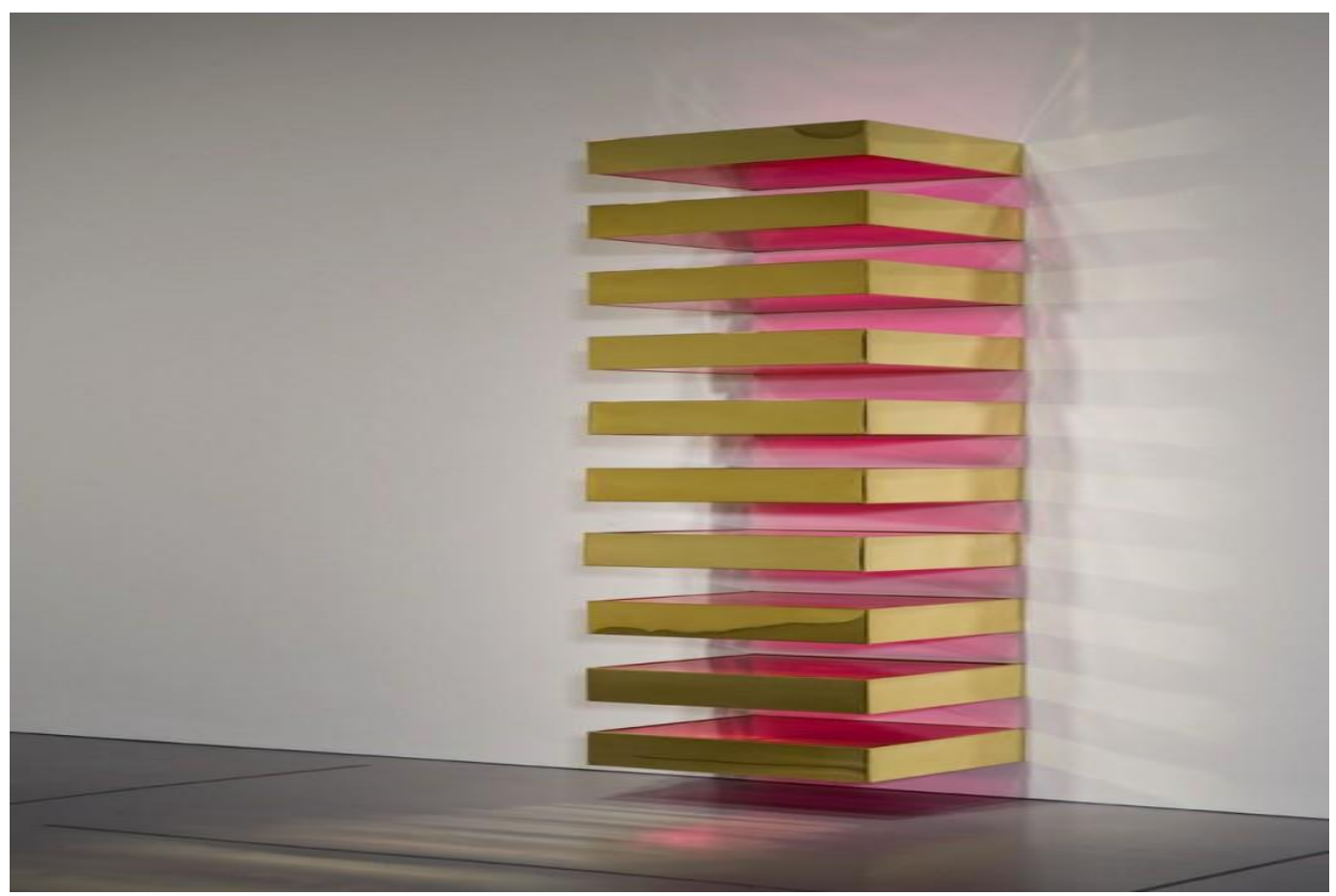

Figure 6: Untitled, by Donald Judd (1968). Materials: Brass and colored fluorescent plexiglass on steel brackets. Size: 10 boxes of 6 x 27 x 24 inches each. Collection: Hirshhorn Museum and Sculpture Garden, Washington, D.C. 


\section{INTERNATIONAL JOURNAL Of RESEARCH - GRANTHAALAYAH \\ A knowledge Repository} Art

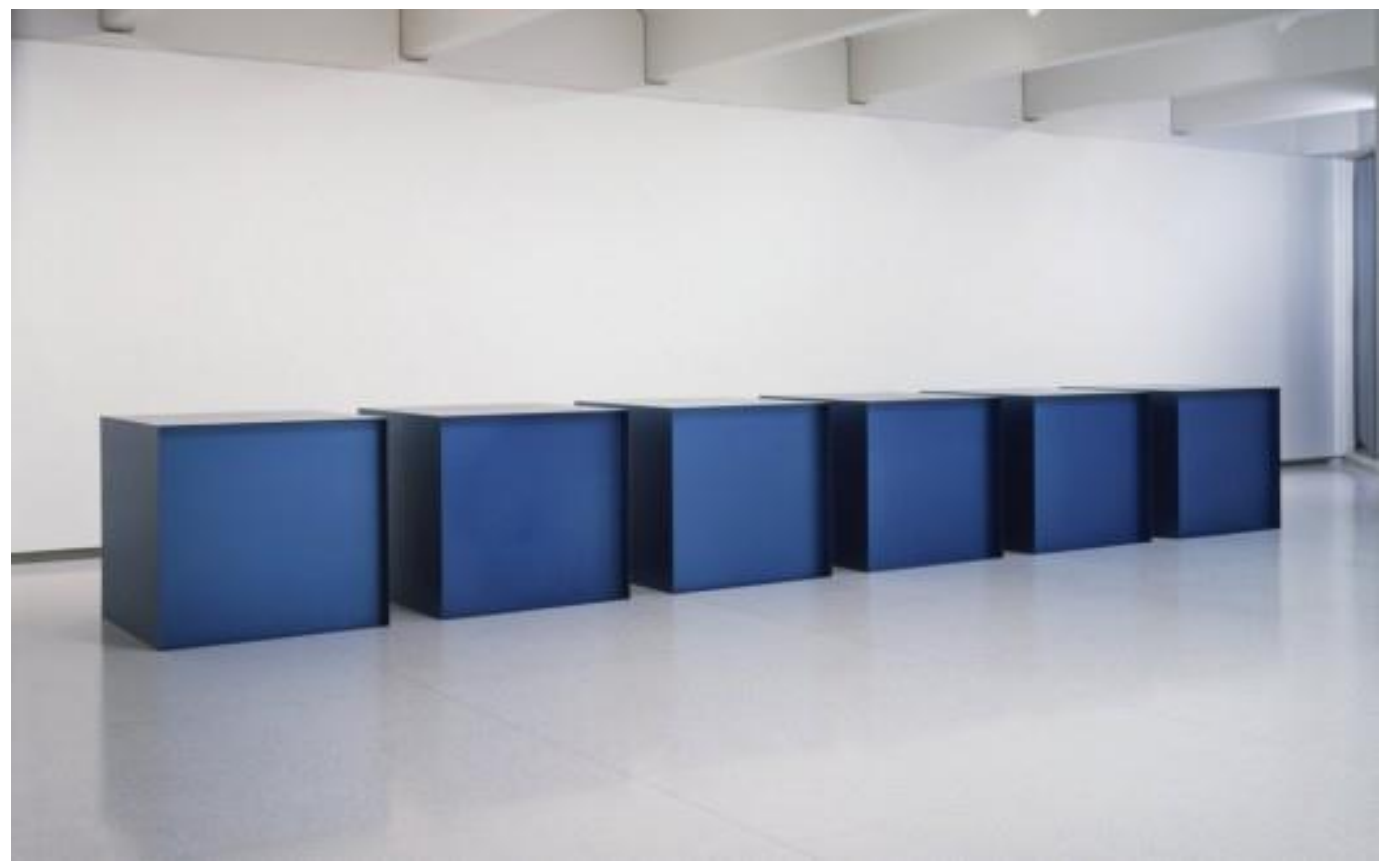

Figure 7: Untitled, by Donald Judd (1971). Material: Anodized aluminum. Size: 6 boxes of 48 x 48 x 48 inches each. Collection: Walker Art Center.

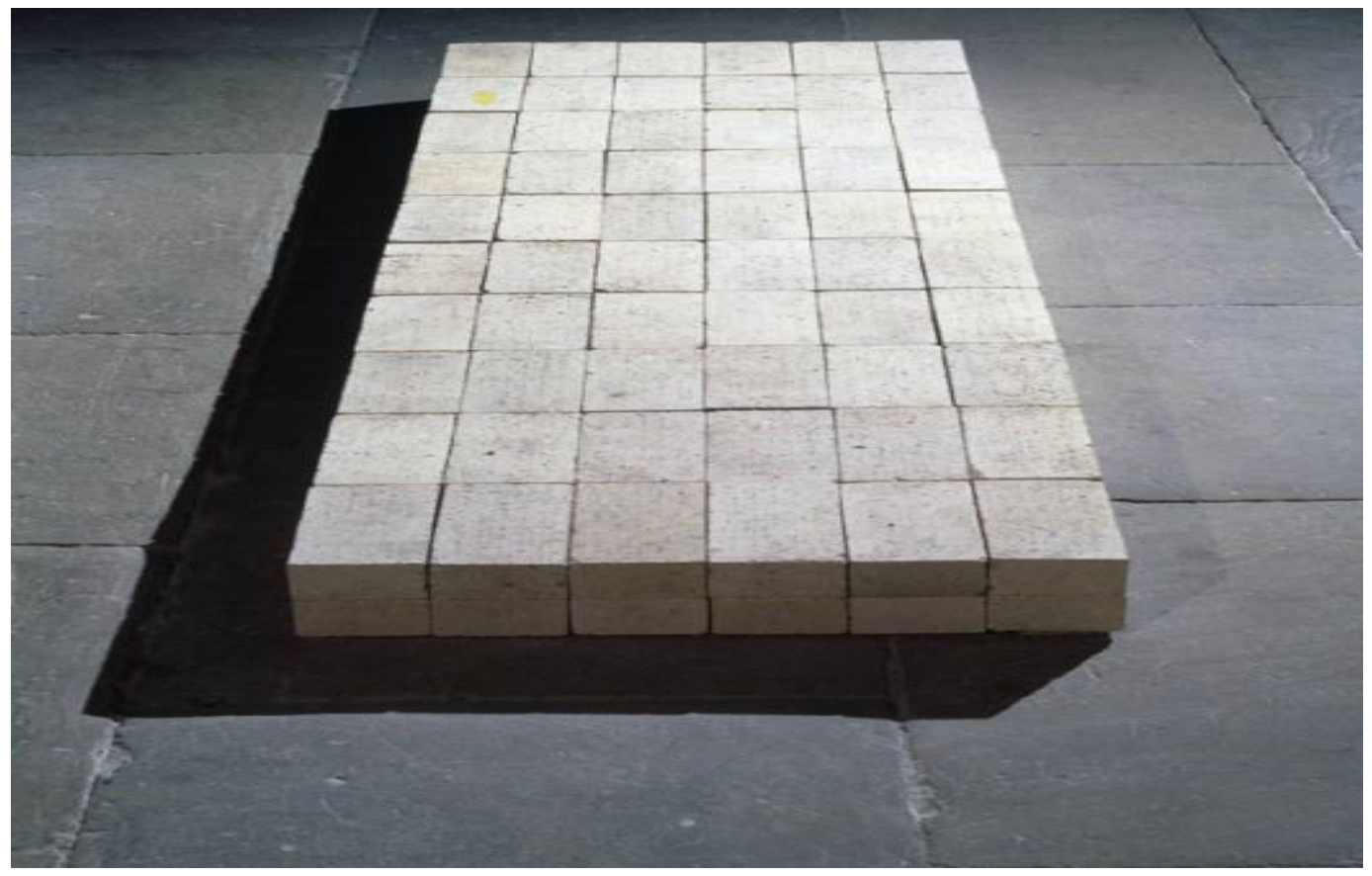

Figure 8: "Equivalent VIII" by Carl Andre (1966). Material: firebricks. Size: 127 x 686 x 2292 mm. Collection: Tate Modern. 


\section{INTERNATIONAL JOURNAL Of RESEARCH - GRANTHAALAYAH \\ A knowledge Repository}

Art

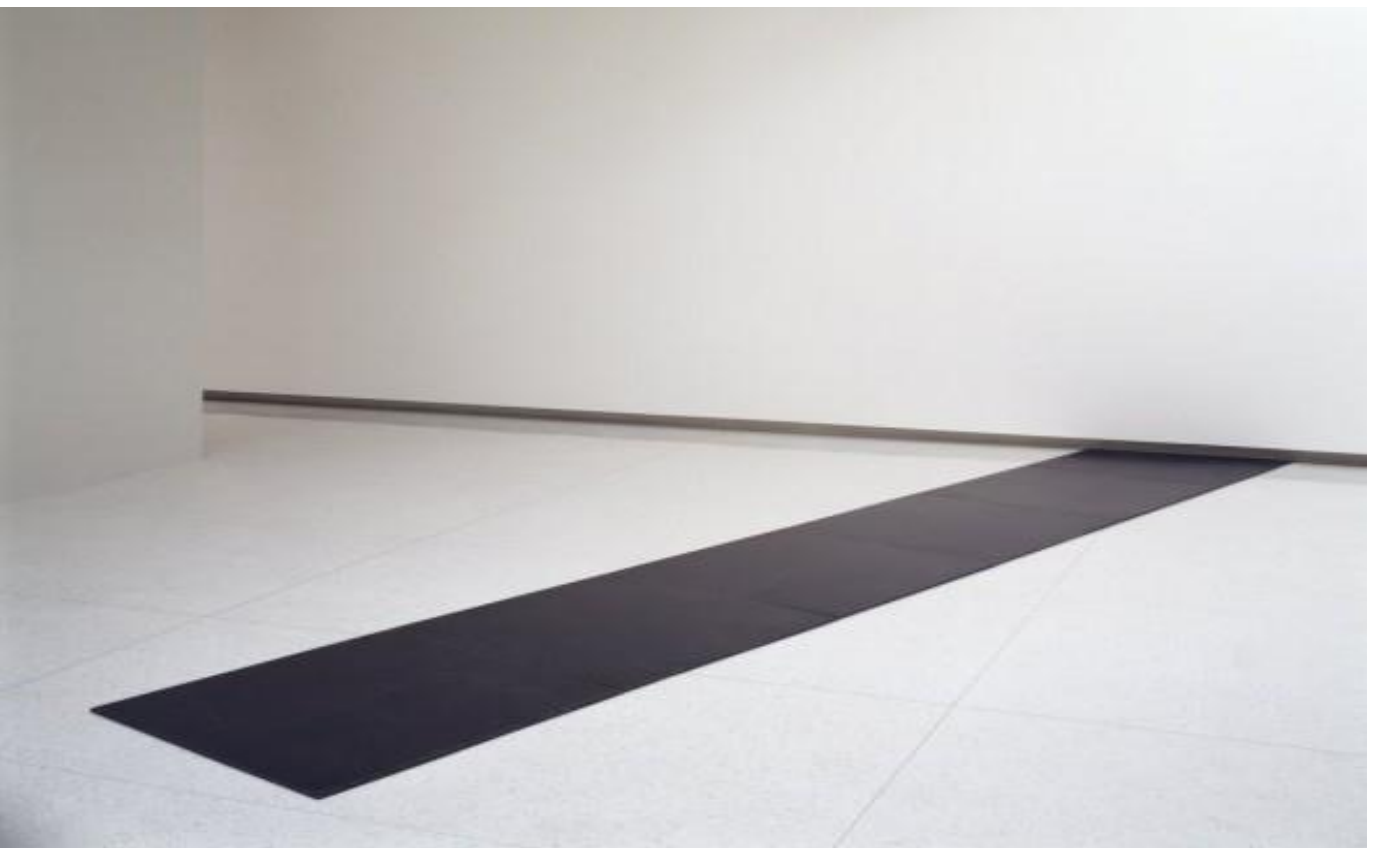

Figure 9: "Slope 2004" by Carl Andre (1968). Material: Steel. Size: overall 0.5 x 204 x 38 inches. Collection: Walker Art Center.

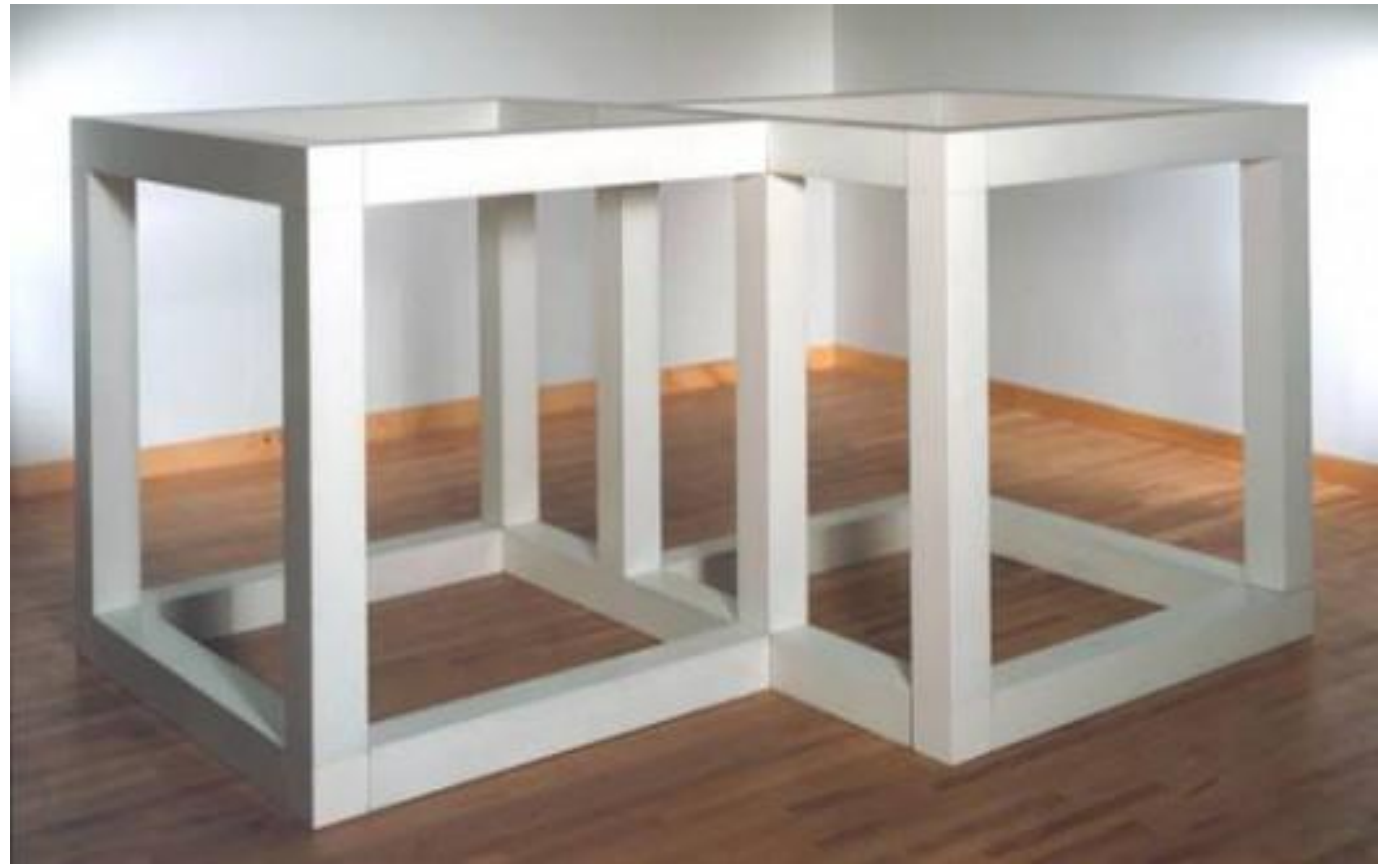

Figure 10: "Two Open Modular Cubes/Half-Off", by Sol LeWitt (1972). Material: Enameled aluminum. Size: 1600 x 3054 x 2330 mm. Collection: Tate Gallery, London 


\section{INTERNATIONAL JOURNAL Of RESEARCH - GRANTHAALAYAH \\ A knowledge Repository} Art

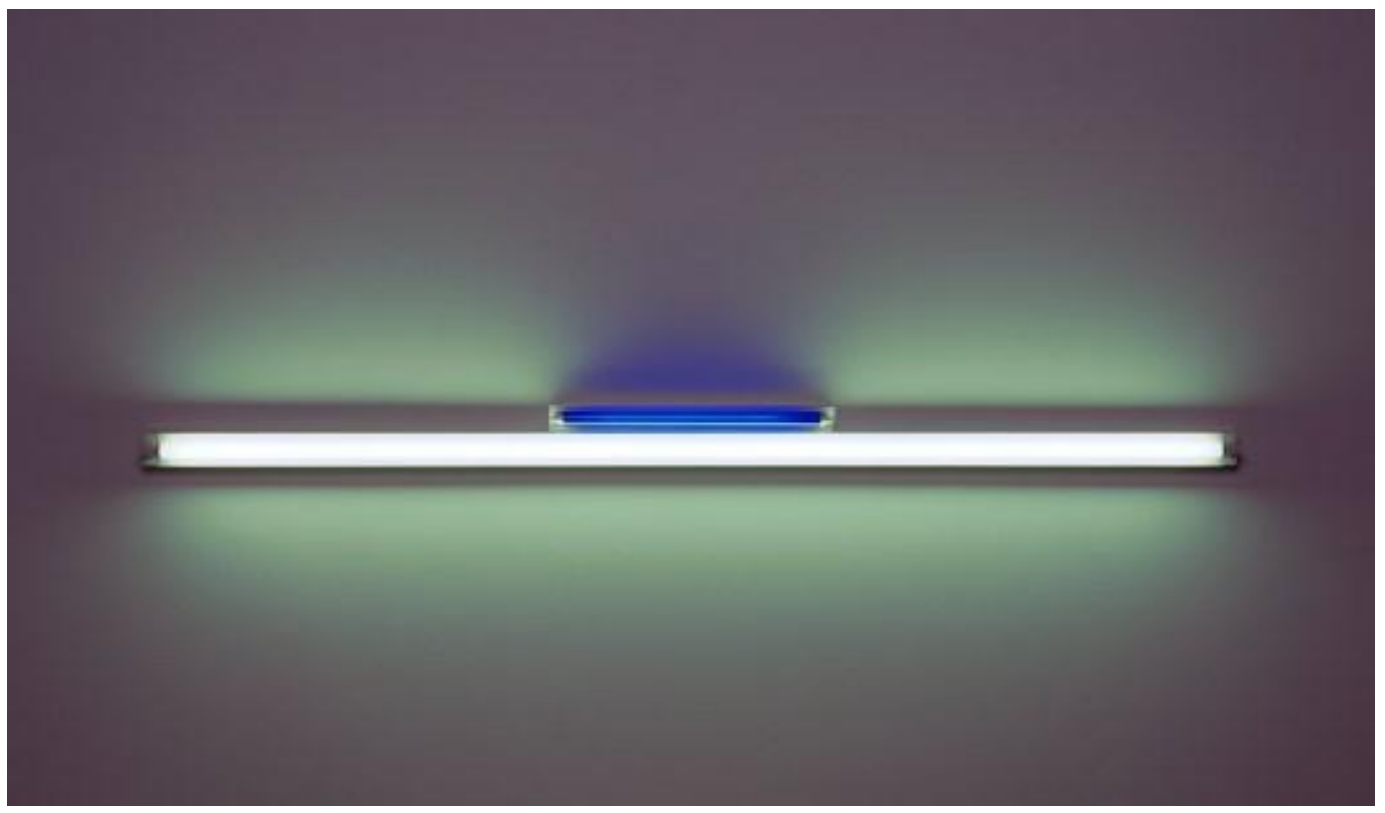

Figure 11: Untitled, by Dan Flavin (1963). Material: Ultraviolet, blue fluorescent tubes and fixtures. Size: 8 x 96 x 4 inches. Collection: Walker Art Center.

\section{PRESENT MINIMAL ART}

By the late 1960s, Minimalism was beginning to show signs of breaking apart as a movement, as various artists who had been important to its early development began to move in different directions.However, critics agree that Minimalism formed a "crux" or turning point in the history of modernism and the movement remains hugely influential today.

\section{REFERENCES}

[1] Wikipedia: http://en.wikipedia.org/wiki/Minimalism

[2] Wikipedia: http://en.wikipedia.org/wiki/Abstract_art

[3] How to Paint and Draw (8nd Edition), by Bodo W. Jaxtheimer, Thames and Hudson Ltd, London, 1982.

[4] URL: http://www.theartstory.org/movement-minimalism.htm

[5] URL: http://www.creativeglossary.com/art-stylesmovements/minimalism.html

[6] URL: http://www.artrepublic.com/art_terms/32-minimalism.html

[7] URL: http://www.visual-arts-cork.com/history-of-art/minimalism.htm

[8] URL: http://www.visual-arts-cork.com/abstract-art.htm

[9] URL: http://abstractcritical.com/article/minimalism-and-abstract-expressionism-the-gapbetween/

[10] URL: http://www.moma.org/learn/moma_learning/themes/minimalism 